\title{
Identifying Potential Mutations Responsible for Cases of Pulmonary Arterial Hypertension
}

This article was published in the following Dove Press journal:

The Application of Clinical Genetics

\author{
Emmanuel Eroume-A Egom ${ }^{1-3}$ \\ Roger Moyou-Somo ${ }^{2}$ \\ Jean Louis Essame Oyono ${ }^{2}$ \\ Rene Kamgang ${ }^{2}$ \\ 'Institut du Savoir Montfort (ISM), \\ Hôpital Montfort, Ottawa, ON, Canada; \\ ${ }^{2}$ Laboratory of Endocrinology and \\ Radioisotopes, Institute of Medical \\ Research and Medicinal Plants Studies \\ (IMPM), Yaoundé, Cameroon; ${ }^{3}$ Reflex \\ Medical Centre Cardiac Diagnostics, \\ Reflex Medical Centre, Mississauga, ON, \\ Canada
}

Correspondence: Emmanuel Eroume-A Egom

Institut du Savoir Montfort (ISM), Hôpital Montfort, 7I 3 Montreal Rd, Ottawa, ON, KIK OT2, Canada

Email egomemmanuel@gmail.com

\begin{abstract}
Pulmonary Arterial Hypertension (PAH) is a progressive and devastating disease for which there is an escalating body of genetic and related pathophysiological information on disease pathobiology. Nevertheless, the success to date in identifying susceptibility genes, genetic variants and epigenetic processes has been limited due to PAH clinical multi-faceted variations. A number of germline gene candidates have been proposed but demonstrating consistently the association with PAH has been problematic, at least partly due to the reduced penetrance and variable expressivity. Although the data for bone morphogenetic protein receptor type 2 (BMPR2) and related genes remains undoubtedly the most extensive, recent advanced gene sequencing technologies have facilitated the discovery of further gene candidates with mutations among those with and without familial forms of PAH. An in depth understanding of the multitude of biologic variations associated with PAH may provide novel opportunities for therapeutic intervention in the coming years. This knowledge will irrevocably provide the opportunity for improved patient and family counseling as well as improved PAH diagnosis, risk assessment, and personalized treatment.
\end{abstract}

Keywords: PAH, pulmonary arterial hypertension, genes, mutations, BMPR2, bone morphogenetic protein receptor type 2

\section{Introduction}

Pulmonary arterial hypertension (PAH) is a severe and life-threatening disorder of the pulmonary vasculature that is pathobiologically characterized by abnormal proliferation of endothelial and smooth muscle cells, and surrounding adventitial expansion leading to an increase in pulmonary vascular resistance which in turn increases afterload of the right ventricle (Figure 1). ${ }^{1-4}$ Among the various groups of PH, Group 1 PAH includes idiopathic (IPAH), heritable (HPAH, formerly familial $\mathrm{PAH}$ ) and PAH associated with a variety of other systemic disorders or drug/toxin exposures. $^{3,5}$ Despite remarkable advancements in the treatment over the past 30 years, PAH remains a fatal disease for incident cases characterized by increased morbidity and mortality. ${ }^{3,6}$ Unfortunately, no single pharmacological agent tested to date has demonstrated the ability to reverse or least halt $\mathrm{PAH}$, and there is as yet no prospect of cure of this devastating disease. Therefore, there is an urgent unmet need to further our pathobiological mechanisms and understanding to promote new therapeutic strategies and clinical practice. ${ }^{3,6,7}$

Since its initial descriptions (hemodynamically) in 1951 by David Dresdale et al as a clinical entity that could occur in either isolation (IPAH) or in families $(\mathrm{HPAH})$, there has been significant progress in our understanding of the molecular 


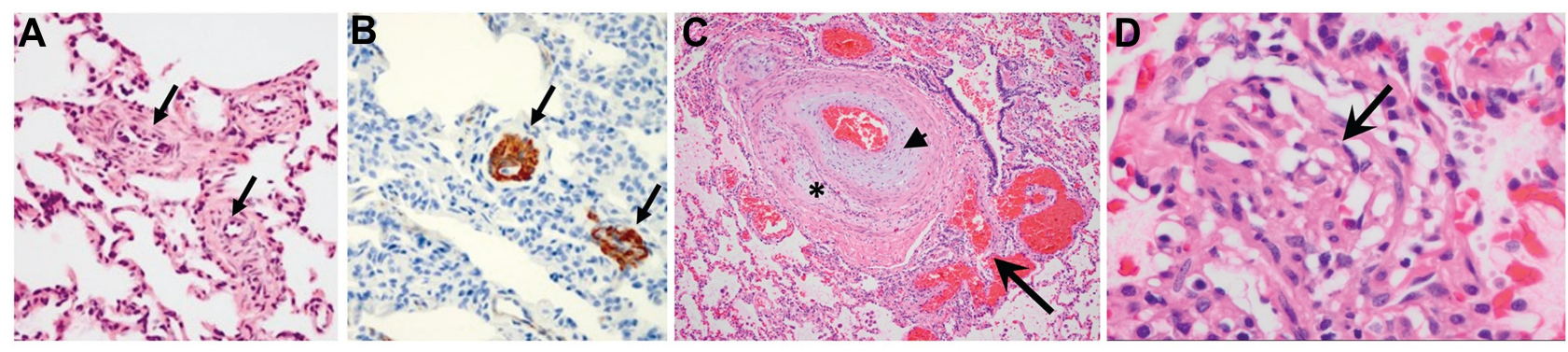

Figure I Typical histopathological characteristics of PAH.

Notes: (A, B) Lung tissue from a HPAH patient with a mutation in the CAVI gene (grades I and II). Hematoxylin and eosin staining may show pulmonary vascular smooth muscle cell proliferation, medial thickening of small pulmonary arteries (A, arrows), as confirmed by immunohistochemical staining of $\alpha$-smooth muscle actin (B, arrows). ${ }^{17}$ (C, D) Lung biopsy from a HPAH patient with a mutation in the KCNK3 gene. (C) Fibrosis (arrowhead), intimal proliferation, and recanalization (asterisk), with an adjacent angiomatoid lesion (arrow) typical of HPAH/IPAH (grade III). (D) Grade IV PAH disease may include plexiform lesions characterized by intimal and endothelial proliferation (arrow). ${ }^{18}$ Copyright (2017. John Wiley and Sons. Reproduced from Ma L, Chung WK. The role of genetics in pulmonary arterial hypertension. J Pathol. 20I7;24I(2):273$280{ }^{4}$

and genetic factors that promote $\mathrm{PAH}^{3,8,9}$ Although the exact pathobiological mechanisms responsible for both idiopathic and heritable forms of PAH (IPAH and HPAH) are still not fully understood, a number of potentially causative mutations in genes primarily related to PAH as well as genetic and epigenetic modifiers of disease expression have been discovered via advanced genetic and genomic techniques including but not limited to conventional linkage analysis and next-generation sequencing technologies. ${ }^{10}$ The effects of these genetic risk factors may interplay with those of environmental factors and other signaling molecule to alter pulmonary vascular structure and function. ${ }^{4,6}$ Understanding the genetic etiology of $\mathrm{PAH}$ as well as the molecular variants that modulate pulmonary vascular resistance should facilitate better diagnosis and development of novel therapeutic strategies and clinical practice in the future.

\section{Genetics of PAH}

Familial cases of PAH have long been reported and are transmitted in an autosomal dominant manner, but HPAH does not affect all individuals at risk due to reduced penetrance. ${ }^{9,11,12}$ Although the mechanisms which reduce penetrance are unknown, several features of HPAH highlight the variable expressivity of this disorder, and these include the fact that females are preferentially affected ( $\sim 2: 1$ female: male ratio) but also the highly variable age of diagnosis. ${ }^{3,13,14}$ HPAH accounts for about $6 \%$ of $\mathrm{PAH} .{ }^{15}$ This is likely an underestimate as a significant number of individuals with PAH that is heritable (HPAH) may actually be misclassified as IPAH due to reduced penetrance of the known PAH-associated genes, as well as de novo genetic mutations at conception. ${ }^{3,16}$ In fact, evidence suggests that up to $20 \%$ of cases previously classified as IPAH harbor identifiable mutations in PAHassociated genes and thus pose a hereditary risk to other family members. ${ }^{17}$

The first evidence of genetic contributions to PAH was identified following linkage analysis in which mutations in the gene encoding bone morphogenetic protein receptor type 2 (BMPR2), a member of the transforming growth factor-beta (TGF- $\beta$ ) receptor superfamily, were responsible for approximately $75 \%$ of cases of HPAH and $20 \%$ of patients with IPAH. ${ }^{15,18}$ The estimated penetrance of BMPR2 mutations is approximately $20 \%$ and may be regulated by the level of expression of the normal BMPR2 allele, ${ }^{19}$ which appears to be lower in female subjects compared with male with $\mathrm{PAH} .{ }^{20}$ In addition, patients with PAH and disease-causing BMPR2 mutations are diagnosed and tend to die approximately 10 years earlier than those without mutation. ${ }^{3}$ BMPR2 mutation PAH subjects are also unlikely to respond to acute vasodilator testing during right heart catheterization and are thus less likely to benefit from therapy with calcium channel blockade. ${ }^{17,21}$

Since its initial descriptions, over 400 different mutations in BMPR2 have been definitively associated with HPAH, highlighting the relevance of the TGF- $\beta$ superfamily of receptors and signaling to $\mathrm{PAH} .{ }^{3,4,17}$ Further genes related to TGF- $\beta$ superfamily receptor members or related downstream signaling molecules have been identified as uncommon causes of PAH in families, including but not limited to activin receptor-like type 1 (ACVRL-1), SMAD family member 4 (SMAD4) SMAD family member 8 (SMAD8; also known as SMAD9), and endoglin $(E N G) .{ }^{4,22-28}$ The TGF- $\beta$ family comprises a large series 
of cytokine growth factors that are involved in the regulation of multiple cellular functions and homeostasis, among them endothelial mesenchymal transition, proliferation, differentiation, migration, apoptosis, and extracellular matrix secretion and deposition. ${ }^{17,29}$ The implication of BMPR2, ALK-1, and ENG as causal genetic factors in HPAH has emphasized the vital role of this signaling pathway to the integrity of the pulmonary vascular bed. ${ }^{17,30}$

\section{HPAH Not Due to Mutations in the TGF $\beta$ Superfamily-Related Genes}

Approximately $20 \%$ of families with demonstrable $\mathrm{HPAH}$ lack detectable mutations in the TGF- $\beta$ pathway. ${ }^{3}$ This has led the scientific community to search for additional mutations which may contribute to PAH pathobiology. Recent application of whole-exome sequencing (WES) has allowed the discovery of several other novel, but biologically plausible PAH-associated genes, including but not limited to CAV1 (involved in BMPR2 membrane localization and signaling) and $K C N K 3$ (a potassium channel that regulates resting membrane potential). ${ }^{31,32}$

\section{PAH Due to KCNK3 Mutations}

Mutations in the gene KCNK3 (Potassium two-poredomain channel, subfamily $\mathrm{K}$ member 3 ), which encodes the human $\mathrm{pH}$-sensitive outwardly rectifying potassium channel, appear to be the more frequent of the two new biologically plausible PAH-associated genes. ${ }^{3}$ Although genetic and electrophysiological data suggest that $K C N K 3$ (also known as TASK-1) mutation may be a rare genetic cause of HPAH and IPAH, its specific role in PAH pathobiology remains incompletely understood. ${ }^{4,32}$ $\mathrm{KCNK} 3$ is ubiquitous and highly expressed in animal and human pulmonary artery smooth muscle cells. ${ }^{4}$ Regulation of ion channels is a hot topic in vascular physiology, given its crucial role in not only vasoconstriction but also vascular remodeling. ${ }^{3}$ The function of $\mathrm{KCNK} 3$ is to conduct leak $\mathrm{K}^{+}$current, regulate pulmonary vascular tone and maintain the resting membrane potential. ${ }^{4}$ Activation of $\mathrm{KCNK} 3$ may cause $\mathrm{K}^{+}$efflux, membrane hyperpolarization and vasodilatation., ${ }^{4,3-36}$ A loss of function of KCNK3 may thus promote calciummediated vasoconstriction, which may, at least in part explain to date lack of response to vasodilator testing. ${ }^{3}$ Single nucleotide polymorphisms in another gene in the potassium channel family (KCNA5, potassium voltage- gated channel subfamily A member 5) have also been identified in individuals with HPAH and IPAH. ${ }^{4}$ Whether $K C N A 5$ may be a genetic risk factor for PAH and thus may play important roles in determining pulmonary vascular tone, cell proliferation, apoptosis and oxygen sensing remains unclear. ${ }^{4,37,38}$ A recent meta-analysis including 7583 subjects indicates that KCNA5 mutation may not represent a genetic susceptibility factor, at least for systemic sclerosis-associated $\mathrm{PAH}^{39}$

\section{PAH Due to Caveolin I Mutations}

Mutations in caveolin $1(C A V 1)$ are a rare cause of HPAH and IPAH. ${ }^{31} \mathrm{CAV} 1$ encodes a membrane protein, which is required to form flask-shaped invaginations of the plasma membrane (known as caveolae) and plays a crucial role in mediating TGF- $\beta$, G-protein and nitric oxide signaling in PAH. $^{4}$ Caveolae are ubiquitous and highly expressed in adipocytes, endothelial cells, and fibroblasts. ${ }^{40}$ Mechanisms of $C A V 1$ mutation in HPAH and IPAH have been extensively evaluated. In experimental models, Cavl may be expressed in endothelial and epithelial cells of the septum which is located between the alveolar space and the pulmonary blood capillaries. ${ }^{41}$ In humans, CAV1 may be detected in the endothelium of arteries in the lungs. ${ }^{31}$ Although heterozygous $C A V 1$ mutations have been identified in isolated $\mathrm{PAH}$ or PAH associated with lipodystrophy, its specific role in PAH pathobiology remains incompletely understood. ${ }^{40,42}$ Evidence suggests that CAV1 may modify TGF- $\beta$ signaling including an inhibition of BMP signaling pathway in various cell types, such as vascular smooth muscle cells; ${ }^{43,44}$ and separately, reduction in CAV1 may be associated with an upregulation of STAT3 which may in turn, directly reduce BMP signal transduction-both these observations suggest a mechanistic link between $C A V 1$ and $B M P R 2$ mutations in the pathobiology of PAH. ${ }^{3,45,46}$ Moreover, CAV1 may inhibit endothelial nitric oxide synthase (eNOS) activity, and loss of CAV1 may allow uncoupled eNOS to produce pathological reactive oxygen species that promote $\mathrm{PAH} .{ }^{3,41,47-50}$

\section{PAH Due to Other Rare Gene Mutations}

Several other new genes predisposing to PAH have been identified during the last decade. Eyries et al found that a loss-of-function mutation in the $K D R$ gene may cause a particular form of PAH characterized by low diffusing capacity for carbon monoxide and radiological evidence of interstitial lung disease. ${ }^{51}$ Chida et al identified two missense mutations in NOTCH3 (which encode a group of $300-\mathrm{kD}$ single-pass transmembrane receptors) in IPAH 
patients. ${ }^{52}$ The authors found that these mutations may be involved in cell proliferation and viability. ${ }^{52}$

\section{Rare Disease Alleles Underlying PAH}

\section{Hereditary Hemorrhagic Telangiectasia}

Hereditary hemorrhagic telangiectasia (HHT) is a rare autosomal dominantly inherited vascular dysplasia characterized by the appearance of mucocutaneous telangiectasias and arteriovenous malformations (AVMs), including AVMs of the pulmonary, hepatic, and cerebral circulations, but these lesions may be cryptic or develop later in the course. ${ }^{3}$ The disease is caused by pathogenic mutations in ENG located on Chromosome 9 or ACVRL1 located on Chromosome 12, which are identified in $80-85 \%$ of HHT patients; while SMAD4 mutations, which are also associated with juvenile polyposis, are found in $1-2 \%$ of HHT $^{53,54}$ Another genetic cause for HHT is mutations in Growth differentiation factor 2 ( $G D F 2$, previously known as bone morphogenetic protein 9, BMP9) ${ }^{55,56}$ Mutations in GDF2/BMP9 have been identified in HHT-associated $\mathrm{PAH}$ as well as isolated $\mathrm{PAH} .{ }^{4,57}$ Wang et al performed an exome-wide gene-based burden analysis on two independent case-control studies, including a total of 331 IPAH cases and 10508 controls, and identified rare bone morphogenetic protein $9(B M P 9)$ mutations in $6.7 \%$ of the cases, ranking this gene second to $B M P R 2 .{ }^{58}$ The authors also demonstrated that the BMP9 mutations led to impaired BMP9 secretion and reduced anti-apoptosis ability in pulmonary vascular endothelial cells. ${ }^{58}$ It is estimated that roughly one-third of HHT patients may have pulmonary AVMs, and a small proportion $(<1 \%)$ of HHT subjects may have PAH that is clinically and histopathobiologically indistinguishable from other HPAH, while others have PAH secondary to pulmonary arteriovenous fistulas. ${ }^{4,30}$ Mutations of ACVRL1 appear to be the most likely underlying causative factor in these individuals. ${ }^{4} \mathrm{Up}$ to $20 \%$ of all detected mutations in ACVRL1 may be associated with the development of PAH, and, of these, $81 \%$ may have PAH. ${ }^{4,59,60}$ In rare instances, mutations of ACVRL1 may cause PAH without HHT. ${ }^{61,62}$

\section{Pulmonary Veno-Occlusive Disease and Pulmonary Capillary Hemangiomatosis}

Pulmonary veno-occlusive disease (PVOD) and pulmonary capillary hemangiomatosis $(\mathrm{PCH})$ are rare causes of PAH with clinical presentation which may be indistinguishable from each other, and from $\mathrm{PAH}^{3}$ As a result, the current WHO clinical classification combines these diagnoses in a single subcategory of Group 1 PAH, labeled as 1': PVOD and/or PCH. ${ }^{2,3,63}$

Eyries et al performed whole-exome sequencing and identified recessive mutations in EIF $2 A K 4$ that may cosegregate with PVOD in all the 13 families evaluated. ${ }^{64}$ EIF2AK4 (also called GCN2) encodes Eukaryotic Translation Initiation Factor 2 Alpha Kinase, a serinethreonine kinase that belongs to a family of kinases that modulate angiogenesis in response to cellular stress. ${ }^{3}$ The authors also reported biallelic EIF2AK4 mutations in 25\% of histologically confirmed sporadic cases of PVOD. ${ }^{64}$ All identified $E I F 2 A K 2$ mutations disrupted the function of the gene, thus supporting the notion that EIF2AK2 mutations may be the major gene that is linked to the development of PVOD. ${ }^{64}$ Interestingly, the authors found that subjects with EIF2AK4 mutations had variable age at diagnosis and were more likely to be younger than PVOD patients without the mutation. ${ }^{64}$ Independently, Best et al performed an exome sequencing to identify a candidate gene for $\mathrm{PCH}$ and discovered biallelic EIF2AK4 gene mutations as the likely cause of autosomal-recessive $\mathrm{PCH}$ in familial and some nonfamilial cases. ${ }^{65}$

The above suggested genetic association for PVOD and PCH further supports the notion that these two clinical entities may represent a single disease spectrum. ${ }^{3}$ EIF $2 A K 4$ mutations also indicate the potential heritable nature of these clinical entities.

\section{Pediatric PAH}

Pediatric PAH includes IPAH, HPAH and PAH associated with other conditions such as congenital heart disease and abnormal lung development. ${ }^{4}$ Although the genetics of pediatric PAH has not been extensively evaluated, evidence suggests that PAH in children may have a different genetic pathobiology from that in adults. ${ }^{4}$ Grünig et al performed a systematic genetic and clinical family screening in 13 children with IPAH and found that none of the assessed children had mutations in the BMPR2 gene or a history of HHT. ${ }^{66}$ In a cohort of 54 patients with IPAH or HPAH whose onset of disease was at $<16$ years of age, 18 $B M P R 2$ and 7 ACVRL 1 mutation carriers were identified, and these had a worse outcome than mutation noncarriers. ${ }^{67}$ A study of 50 patients with PAH associated with congenital heart disease (CHD) demonstrated that $26 \%$ of them may have BMPR 2 mutations. ${ }^{68}$ In a mixed cohort of 40 pediatric PAH cases, including 29 IPAH/ 
HPAH and 11 PAH-CHD, mutations of the BMPR2, ACVRL1, and ENG gene, respectively, occurred in $27.5 \%$ of IPAH/HPAH patients and even in $18.2 \%$ with PAH-CHD. ${ }^{69}$ The differences in genetic results in various PAH studies in children may be the result of a combination of factors, including but not limited to different genetic backgrounds, small sample sizes and selection criteria such as whether the PAH was associated with other diseases. ${ }^{4}$ Pediatric patients with BMPR2 mutations appear less likely to respond to acute vasodilator testing (thus unlikely to benefit from calcium channel blockade therapy) than mutation-negative subjects and may have more severe disease at diagnosis. ${ }^{70}$

TBX4 is a transcription factor in the T-box gene family, expressed in the mesenchyme of the lung, the limbs, and the atrium of the heart. ${ }^{4}$ In a cohort of 20 consecutive pediatric cases with IPAH or HPAH and 49 adults with PAH, Kerstjens-Frederikse et al performed an array-comparative genomic hybridization analysis and found that TBX4 mutations were associated with pediatric $\mathrm{PAH}$, but that the prevalence of PAH in adult TBX4 mutation carriers was low. ${ }^{71} \mathrm{Zhu}$ et al performed a WES screen of 155 paediatric- and 257 adult-onset PAH patients and found that in addition to $B M P R 2$, there was significant enrichment of $T B X 4$ (a gene linked to small patella syndrome) mutations in paediatric- compared with adult-onset subjects, and $T B X 4$ carriers had younger mean age-ofonset compared with $B M P R 2$ carriers. ${ }^{72}$ Haarman et al performed a targeted next-generation sequencing to explore genotype-phenotype associations and outcomes in 70 children with HPAH/IPAH from the Dutch National registry and to explore genotype-phenotype associations and outcome. ${ }^{73}$ The authors found $T B X 4$ variant carriers may have favorable outcome (higher survival rate) as compared with individuals carrying $B M P R 2 / A C V R L 1 /$ $K C N K 3$, or EIF2AK4 mutations. ${ }^{73}$ In a Spanish cohort of 165 adult-onset PAH, TBX4-related forms of $\mathrm{PAH}$ appeared to have a more benign course and late diagnosis was the only predictor of worse outcomes in $\mathrm{HPAH}{ }^{74}$

Several other new genes predisposing to pediatric $\mathrm{PAH}$ have been identified during the last decade. Bohnen et al performed an exome sequencing to identify novel genes in a cohort of 99 pediatric and 134 adult-onset group I PAH patients and discovered novel and rare missense variants in ABCC8, which encodes SUR1 (sulfonylurea receptor 1)-a regulatory subunit of the ATP-sensitive potassium channel. $^{75}$ Gräf et al perform whole-genome sequencing in 1038 PAH index cases and 6385 PAH-negative control subjects and found novel mutations in GDF2 (which codes the ligand for the endothelial BMPR2/ACVRL1 receptor complex) and identified significant overrepresentation of rare variants in $A T P 13 A 3$ (a poorly characterised P-type ATPase of the P5 subfamily which loss of function may inhibit proliferation and increase apoptosis of endothelial cells), AQP1 (codes for the Aquaporin-1 known to promote endothelial cell migration and angiogenesis, while its inhibition may ameliorate hypoxia-induced $\mathrm{PH}$ ), and SOX17 (which encodes the SRY-box containing transcription factor 17 , known to promote angiogenesis and arteriovenous differentiation while its deletion may lead to impaired formation of pulmonary vasculature). ${ }^{76}$ The majority of the causal $G D F 2$ variants detected in Gräf et al's cohort was associated with reduced production of GDF2 from cells. ${ }^{76}$ As already hinted, GDF2 gene encodes the circulating BMP9, which is a ligand for the BMP2 receptor. ${ }^{77}$ GDF2 mutations may result in BMP9 loss of function and are likely causal. ${ }^{77}$ These observations raise the intriguing question of whether GDF2 replacement may be a therapeutic strategy in the management of, at least, some patients with HPAH/IPAH. ${ }^{78}$

Other genes may play an important role in pediatric $\mathrm{PAH}$, including mutations in BMPR1B, which is one of the BMP type I receptors that interact with BMP type II receptors and mediates BMP signaling; ${ }^{79,80}$ mutations in NOTCH3, which may be involved in vascular homeostasis and in the TGF- $\beta$ signaling network. ${ }^{52,81,82}$

\section{Npr3 as a Novel Gene for HPAH/ IPAH}

Despite advances in the science of genetics, there are still some patients with HPAH but without any known PAHcausing mutations, indicating there may be other physiologic candidate genes. ${ }^{17}$ Evidence suggests that the NPR3 gene encoding for the Natriuretic Peptide Receptor type $\mathrm{C}$ (NPR-C) may have an important role in the genetics of HPAH. ${ }^{83-86}$ Although still commonly called a natriuretic peptide clearance receptor (and thus largely ignored), ${ }^{87}$ evidence suggests that the NPR3 gene may be a causative factor for skeletal abnormalities. ${ }^{83-86}$ Mice with inactivated NPR3 may exhibit striking skeletal deformities similar to those observed mice with BMPR2. ${ }^{88-92}$ We have recently shown that mice lacking NPR-C exhibit echocardiographic and hemodynamic findings that are similar to those typically seen in humans with $\mathrm{PAH}{ }^{93,94}$ Although the above data are intriguing, there is, of course, 
no guarantee that identifying the causative genes for rodent will be relevant to human PAH.

\section{Genetic and Non-Genetic Modifiers of Risk for PAH}

The complex clinical and epidemiological features of HPAH and IPAH, such as variable age of disease onset both within and between families, female predominance and incomplete penetrance of dominantly inherited mutations, imply the existence of additional genetic and nongenetic factors capable of modulating the likelihood of developing PAH among susceptible subjects. ${ }^{95}$ The lack of complete penetrance suggests that BMPR2 gene mutation may be required but not sufficient to ensure phenotypic expression. ${ }^{3}$ Hamid et al demonstrated that disease penetrance and phenotypic expression may be inversely proportional to the levels of expression of wild-type allele BMPR2 transcript and proteins. ${ }^{19}$ Although the traditional strategy in the PAH field is to evaluate for inherited germline mutations in BMPR2 and other genes, Aldred et al performed genome-wide microarray copy number analysis on pulmonary artery endothelial cells and smooth muscle cells isolated from the lungs of two $B M P R 2$ mutation carriers with $\mathrm{HPAH}$, in the search for a "second (somatic) genetic hit" which may occur de novo in the lungs. ${ }^{96}$ The authors found a somatic mutation within chromosome 13 in a location that includes the SMAD9 gene (which encodes the protein Smad-8, a downstream mediator of BMPR-II signaling) in one subject, suggesting an additional insult that may represent a second hit that further dysregulates the BMP signaling pathway. ${ }^{96}$ This observation supports the notion that somatic mutations in the lungs may promote or at least modify PAH penetrance among susceptible subjects, which is a concept well described in cancer pathobiology. ${ }^{97}$

There are also common genetic variations that have been associated with PAH pathobiology. Germain et al conducted a genome-wide association study (GWAS) based on 2 independent case-control studies for BMPR2 mutation-negative HPAH and IPAH, including a total of 625 cases and 1525 healthy subjects. ${ }^{98}$ The authors found a striking association at the CBLN2 locus mapping to $18 \mathrm{q} 22.3$, with the risk allele conferring two-fold increased risk. ${ }^{98}$ Interestingly, the authors found that mRNA levels of CBLN2, which belongs to the cerebellin gene family related to secreted neuronal glycoproteins, were significantly higher in explanted lungs from subjects with $\mathrm{PAH}$ and PAH-derived endothelial cells. ${ }^{98}$
As already hinted, HPAH and IPAH preferentially affect females more than males, which suggests that sex hormones may modify and influence penetrance of PAH. White et al examined the influence of gender on the development of $\mathrm{PAH}$ as well as investigating how this is modulated by female hormones, using a genetic-based model of rodent $\mathrm{PAH}$, which was developed by overexpressing the serotonin transporter (SERT). ${ }^{99}$ The authors found that only female mice that overexpress SERT (SERT+ mice) developed PAH features, which were abolished by ovarian removal. ${ }^{99}$ Following hypoxia exposure, only female SERT + mice developed severe PAH features, which were also attenuated by ovarian removal. ${ }^{99}$ Interestingly, chronic administration of estradiol re-established the PAH phenotype. ${ }^{99}$ Consistently, West et al demonstrated that female but not male BMPR2 mutation-positive PAH patients had tenfold lower expression of the estrogen metabolizing Cytochrome P450 1B1 (CYP1B1) gene than carriers unaffected by the disease. ${ }^{100}$ In fact, lowered levels of CYP1B1 may result in increased local estrogen level, which in turn may increase the risk of PAH phenotype. ${ }^{100}$ Other work supported the role of common variations in genes and genetic polymorphisms related to both estrogen signaling and metabolism in the pathobiology of PAH. ${ }^{101,102}$

There is tremendous current interest in the role of epigenetics in PAH pathobiology. The first epigenetic basis for PAH was demonstrated by Archer et al. ${ }^{3,103}$ The expression and activity of mitochondrial superoxide dismutase 2 (SOD2) are known to be reduced in the pulmonary artery smooth muscle cells of experimental PAH and humans with PAH. ${ }^{3,103}$ The authors elegantly demonstrated that SOD2 deficiency was not due to gene mutation, rather the SOD2 gene was epigenetically silenced by hypermethylation of a $\mathrm{CpG}$ island in an enhancer region within intron 2 and the promoter of SOD2. ${ }^{3,103}$ In addition, there is growing interest in the contribution of non-coding RNA such as microRNA (miRs) to the pathobiology of $\mathrm{PAH}$, and tremendous progress has been made to mature our understanding of the integrative functions of these crucial molecular regulators in this disease..$^{3,104-106}$

\section{From Genetics to Pharmacological Treatment}

Recent evidence suggests that targeting molecular pathways highlighted by genetic studies may provide promising new approaches for the treatment of PAH (Figure 2). Long et al demonstrated that BMP9 administration may enhance 


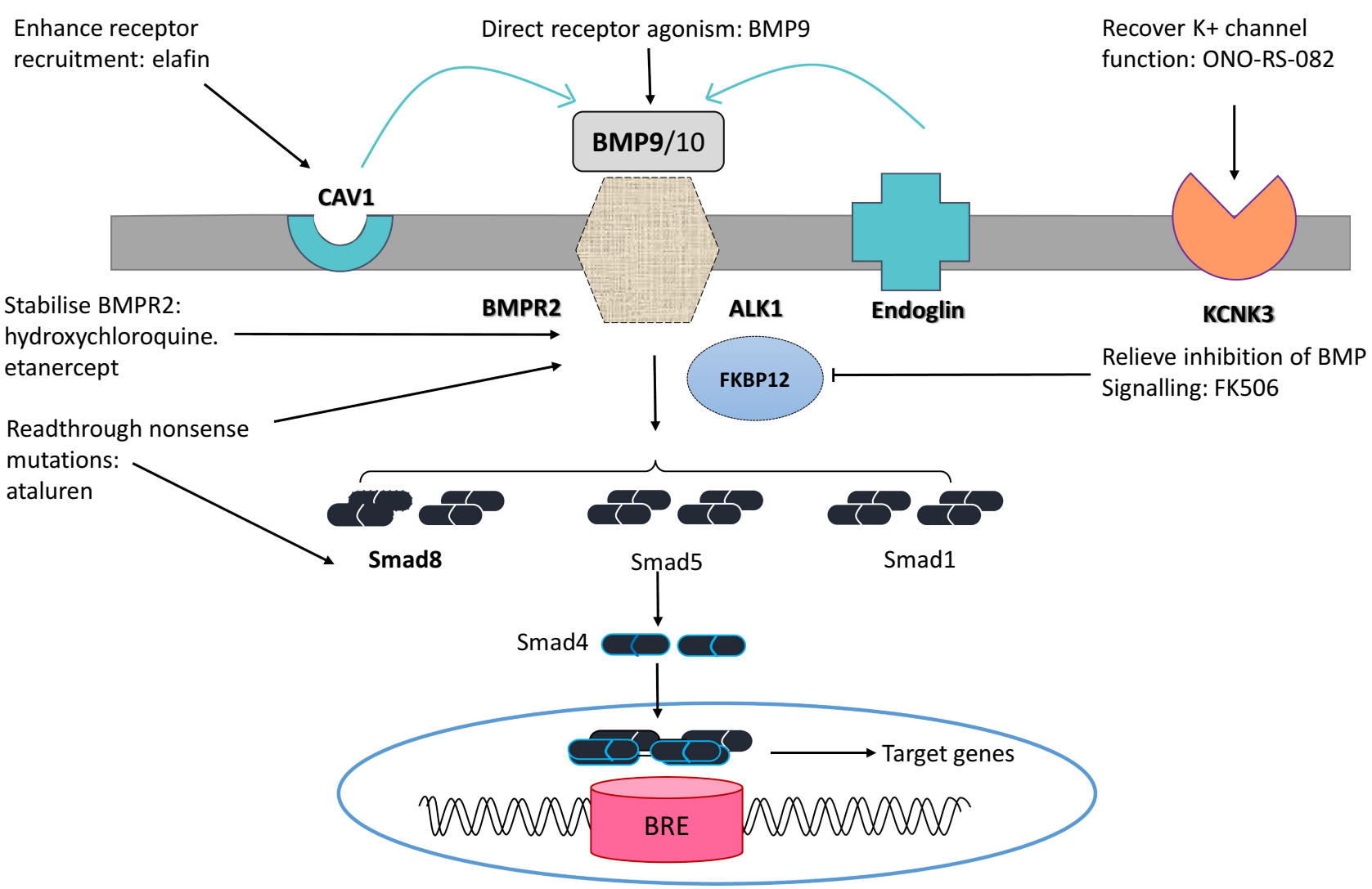

Figure 2 From genetics to pharmacological treatment.

Notes: Bone morphogenetic protein receptor II, BMPR-II; BMP-responsive element, BRE; Caveolin-I, CAVI; 12-kDa FK506-binding protein, FKBPI2. BMP-II signaling in pulmonary vascular endothelial cells may be mediated by the ligands BMP9 and BMPI0 through the ALKI/BMPR2 receptor complex. Endoglin may serve as an accessory receptor. Pathway may be mediated via phosphorylation of the receptor Smads (SmadI, 5 and 8), which in turn may interact with Smad4 and translocate to the nucleus, modulating genes that contain BREs. CAVI may promote receptor colocalization, while KCNK3 encodes a potassium channel that may enhance pulmonary vascular tone. Genes that are mutated in HPAH are in bold. Potential therapeutic strategies targeted to these signaling pathways may include: administration of BMP9 ligand, enhancing availability of functional BMPR2 receptors (hydroxychloroquine, etanercept), enhancing readthrough of nonsense mutations to restore functional BMPR2 or Smad8 protein (ataluren), promoting downstream signaling by relieving FKBPI2 inhibition of BMP type I receptors (FK506), enhancing CAVI-mediated receptor recruitment (elafin), or recovering KCNK3 potassium-channel current (ONO-RS-082). Adapted with permission from Morrell NW, Aldred MA, Chung WK, et al. Genetics and genomics of pulmonary arterial hypertension. Eur Respir J. 2019;53(I):1801899. ${ }^{107}$

endothelial BMPR-II-mediated signaling and reverse established PAH in experimental models bearing a heterozygous knock-in of a human BMPR-II mutation as well as in other experimental PAH models. ${ }^{107}$ The authors demonstrated that BMP9 not only enhances vascular stability and prevents apoptosis of the pulmonary arterial endothelial cells, but also promotes BMPR2 gene expression, which may result in further enhancement of BMPR-II-mediated signaling models. ${ }^{107}$ Therapeutic strategies may, therefore, include translational readthrough of premature stop codons or inhibition of lysosomal degradation of BMPR2. ${ }^{108}$ Drake et al showed that the investigational drug, ataluren, not only may suppress a high proportion of BMPR2 and SMAD9 nonsense mutations in patients with $\mathrm{HPAH}$, but also may correct BMP signaling in vitro. ${ }^{109}$ Treatment with chloroquine and hydroxychloroquine may also enhance the expression of BMPR-II protein and thus restore cell surface BMPR-II via lysosomal degradative pathway. ${ }^{110,111}$ Other potential therapeutic approaches have been suggested in the literature. ${ }^{108}$ The anti-tumour necrosis factor- $\alpha$ (TNF $\left.\alpha\right)$ agent etanercept may reverse $\mathrm{PAH}$ progression by targeting not only the inflammation, but also by reducing BMPR-II cleavage in pulmonary artery smooth muscle cells. ${ }^{112}$ The endogenous elastase inhibitor elafin may reverse the obliterative changes in pulmonary arteries via elastase inhibition and through caveolin-1-dependent amplification of BMPR2 signaling. ${ }^{113}$ Downstream of BMPR2, the calcineurin inhibitor FK506 (tacrolimus) was found to potentiate BMP signaling and to reverse severe experimental PAH, by binding FK-binding protein 12, a repressor of BMP signaling. ${ }^{114}$ Beyond the BMP signaling, Ma et al demonstrated that lossof-function $K C N K 3$ mutations lead to reduced potassium- 
channel current, which, at least for some mutations, may be remedied by the phospholipase $\mathrm{A}_{2}$ inhibitor ONO-RS-082. ${ }^{32}$ Although targeted mutational corrections may be challenging, the above studies make these potential therapeutic strategies a realistic future prospect.

\section{Genetic Testing for PAH}

Clinical genetic testing for HPAH and IPAH is now available to assess risk for family members ie their hereditary predisposition; and in some cases, it is done as part of a broader evaluation as to the etiology of the PAH. ${ }^{3}$ Clinical genetic testing can be offered to any subject with a family history of PAH or IPAH and pediatric PAH. Although still controversial due to the potential psychosocial burden both for the indexed subject as well as for the informed family members, the identification of an heritable disease may provide an opportunity for family screening and closer monitoring in the hope of earlier disease detection and earlier institution of therapy. ${ }^{3}$ After weighing potential risks of genetic screening (psychosocial implications of the probability of developing a deadly disease for which there is no prevention and no specific cure) against potential benefits (including early detection and thus earlier initiation of treatment when indicated), the 6th World Symposium on Pulmonary Hypertension (WSPH) task force recommended that genetic screening be performed under the guidance of a clinical geneticist or genetic counsellor. ${ }^{108}$ There are currently different ways of assessing the genetics of PAH-affected patients. ${ }^{115}$ In addition to commercially available diagnostic PAH/PVOD gene panels, WES or WGS may also be considered for subjects with a negative PAH-causing gene panel. ${ }^{115}$

Although there are no studies to determine the optimal strategy for screening at-risk family members, patient education to ensure awareness of PAH-related symptoms, annual clinical examination and disease surveillance by echocardiogram at least every 3-5 years should be considered. ${ }^{116}$ While there are currently no approved PHspecific therapies for asymptomatic subjects who have tested positive for a PAH-causing mutation, there is no evidence to suggest that early diagnosis will even improve the outcome of these individuals. Primary prevention trials are thus needed to determine what $\mathrm{PH}$-specific therapies may be helpful, and the optimal time to initiate them.

\section{Conclusion}

Since its initial description, limited progress has been made to mature our in-depth understanding of the complex biologic basis of PAH, and this is, at least in part, largely due to its genetic heterogeneity, incomplete penetrance and sexual dimorphism. ${ }^{4}$ As genetic and other types of inherent biologic variations rarely occur in isolation, major advancements can be expected in the next few years in the identification of additional genes as well as genetic and environmental modifiers for PAH. Larger genetic and biomarkers studies, with a close interplay of animal and human approaches will be necessary to better understand the complex genetic networks and events that promote PAH in genetically at-risk subjects.s

\section{Funding}

Institute of Medical Research and Medicinal Plant Study (IMPM). Institut du Savoir Montfort (ISM).

\section{Disclosure}

The authors report no conflicts of interest in this work.

\section{References}

1. Tuder RM, Marecki JC, Richter A, Fijalkowska I, Flores S. Pathology of pulmonary hypertension. Clin Chest Med. 2007;28 (1):23-42. doi:10.1016/j.ccm.2006.11.010

2. Galiè N, Simonneau G. The Fifth World Symposium on Pulmonary Hypertension. J Am Coll Cardiol. 2013;62(25 Suppl):D1-d3.

3. Austin ED, Loyd JE. The genetics of pulmonary arterial hypertension. Circ Res. 2014;115(1):189-202.

4. Galiè N, McLaughlin VV, Rubin LJ, Simonneau G. An overview of the 6th World Symposium on Pulmonary Hypertension. Eur Respir J. 2019;53:1.

5. Humbert M, Sitbon O, Chaouat A, et al. Survival in patients with idiopathic, familial, and anorexigen-associated pulmonary arterial hypertension in the modern management era. Circulation. 2010;122(2):156-163.

6. Rich S, Pogoriler J, Husain AN, Toth PT, Gomberg-Maitland M, Archer SL. Long-term effects of epoprostenol on the pulmonary vasculature in idiopathic pulmonary arterial hypertension. Chest. 2010;138(5):1234-1239.

7. Dresdale DT, Schultz M, Michtom RJ. Primary pulmonary hypertension. I. Clinical and hemodynamic study. Am J Med. 1951;11 (6):686-705.

8. Dresdale DT, Michtom RJ, Schultz M. Recent studies in primary pulmonary hypertension, including pharmacodynamic observations on pulmonary vascular resistance. Bull N Y Acad Med. 1954;30(3):195-207.

9. Tang H, Desai AA, Yuan JX-J. Genetic Insights into Pulmonary Arterial Hypertension. Application of Whole-Exome Sequencing to the Study of Pathogenic Mechanisms. Am J Respir Crit Care Med. 2016;194(4):393-397. doi:10.1164/rccm.201603-0577ED

10. Loyd JE, Primm RK, Newman JH. Familial primary pulmonary hypertension: clinical patterns. Am Rev Respir Dis. 1984;129 (1):194-197. doi:10.1164/arrd.1984.129.1.194

11. Loyd JE, Slovis B, Phillips JA 3rd, et al. The presence of genetic anticipation suggests that the molecular basis of familial primary pulmonary hypertension may be trinucleotide repeat expansion. Chest. 1997;111(6 Suppl):82s-83s. 
12. Simonneau G, Robbins IM, Beghetti M, et al. Updated clinical classification of pulmonary hypertension. $\mathrm{J}$ Am Coll Cardiol. 2009;54(1 Suppl):S43-S54.

13. Larkin EK, Newman JH, Austin ED, et al. Longitudinal analysis casts doubt on the presence of genetic anticipation in heritable pulmonary arterial hypertension. Am J Respir Crit Care Med. 2012;186(9):892-896.

14. Lane KB, Machado RD, Pauciulo MW, et al. Heterozygous germline mutations in BMPR2, encoding a TGF-beta receptor, cause familial primary pulmonary hypertension. Nat Genet. 2000;26 (1):81-84.

15. Rich S, Dantzker DR, Ayres SM, et al. Primary pulmonary hypertension. A national prospective study. Ann Intern Med. 1987;107(2):216-223.

16. Machado RD, Eickelberg O, Elliott CG, et al. Genetics and genomics of pulmonary arterial hypertension. $J \mathrm{Am}$ Coll Cardiol. 2009;54(1 Suppl):S32-S42.

17. Deng Z, Morse JH, Slager SL, et al. Familial primary pulmonary hypertension (gene PPH1) is caused by mutations in the bone morphogenetic protein receptor-II gene. Am J Hum Genet. 2000;67(3):737-744

18. Hamid R, Cogan JD, Hedges LK, et al. Penetrance of pulmonary arterial hypertension is modulated by the expression of normal BMPR2 allele. Hum Mutat. 2009;30(4):649-654.

19. Austin ED, Hamid R, Hemnes AR, et al. BMPR2 expression is suppressed by signaling through the estrogen receptor. Biol Sex Differ. 2012;3(1):6.

20. Sztrymf B, Coulet F, Girerd B, et al. Clinical outcomes of pulmonary arterial hypertension in carriers of BMPR2 mutation. Am $J$ Respir Crit Care Med. 2008;177(12):1377-1383.

21. Johnson DW, Berg JN, Baldwin MA, et al. Mutations in the activin receptor-like kinase 1 gene in hereditary haemorrhagic telangiectasia type 2. Nat Genet. 1996;13(2):189-195.

22. McAllister KA, Grogg KM, Johnson DW, et al. Endoglin, a TGF-beta binding protein of endothelial cells, is the gene for hereditary haemorrhagic telangiectasia type 1. Nat Genet. 1994;8(4):345-351.

23. Shi Y, Massagué J. Mechanisms of TGF-beta signaling from cell membrane to the nucleus. Cell. 2003;113(6):685-700.

24. Fernández LA, Sanz-Rodriguez F, Blanco FJ, Bernabéu C, Botella LM. Hereditary hemorrhagic telangiectasia, a vascular dysplasia affecting the TGF-beta signaling pathway. Clin Med Res. 2006;4(1):66-78.

25. Shintani M, Yagi H, Nakayama T, Saji T, Matsuoka R. A new nonsense mutation of SMAD8 associated with pulmonary arterial hypertension. J Med Genet. 2009;46(5):331-337.

26. Nasim MT, Ogo T, Ahmed M, et al. Molecular genetic characterization of SMAD signaling molecules in pulmonary arterial hypertension. Hum Mutat. 2011;32(12):1385-1389.

27. Drake KM, Zygmunt D, Mavrakis L, et al. Altered MicroRNA processing in heritable pulmonary arterial hypertension: an important role for Smad-8. Am J Respir Crit Care Med. 2011;184(12):1400-1408.

28. Good RB, Gilbane AJ, Trinder SL, et al. Endothelial to Mesenchymal Transition Contributes to Endothelial Dysfunction in Pulmonary Arterial Hypertension. Am J Pathol. 2015;185 (7):1850-1858.

29. Harrison RE, Flanagan JA, Sankelo M, et al. Molecular and functional analysis identifies ALK-1 as the predominant cause of pulmonary hypertension related to hereditary haemorrhagic telangiectasia. J Med Genet. 2003;40(12):865-871.

30. Austin ED, Ma L, LeDuc C, et al. Whole exome sequencing to identify a novel gene (caveolin-1) associated with human pulmonary arterial hypertension. Circ Cardiovasc Genet. 2012;5 (3):336-343.
31. Ma L, Roman-Campos D, Austin ED, et al. A novel channelopathy in pulmonary arterial hypertension. $N$ Engl J Med. 2013;369(4):351-361.

32. Olschewski A, Li Y, Tang B, et al. Impact of TASK-1 in human pulmonary artery smooth muscle cells. Circ Res. 2006;98 (8):1072-1080

33. Gardener MJ, Johnson IT, Burnham MP, Edwards G, Heagerty AM, Weston AH. Functional evidence of a role for two-pore domain potassium channels in rat mesenteric and pulmonary arteries. Br J Pharmacol. 2004;142(1):192-202.

34. Osipenko ON, Evans AM, Gurney AM. Regulation of the resting potential of rabbit pulmonary artery myocytes by a low threshold, O2-sensing potassium current. Br J Pharmacol. 1997;120 (8):1461-1470.

35. Gurney AM, Osipenko ON, MacMillan D, McFarlane KM, Tate RJ, Kempsill FE. Two-pore domain K channel, TASK-1, in pulmonary artery smooth muscle cells. Circ Res. 2003;93(10):957-964.

36. Remillard CV, Tigno DD, Platoshyn O, et al. Function of Kv1. 5 channels and genetic variations of KCNA5 in patients with idiopathic pulmonary arterial hypertension. Am J Physiol Cell Physiol. 2007;292(5):C1837-C1853.

37. Moudgil R, Michelakis ED, Archer SL. The role of $\mathrm{k}+$ channels in determining pulmonary vascular tone, oxygen sensing, cell proliferation, and apoptosis: implications in hypoxic pulmonary vasoconstriction and pulmonary arterial hypertension. Microcirculation. 2006;13(8):615-632.

38. Ai J, Liu M, Shuai Z, et al. KCNA5 gene variation is not associated with the pulmonary hypertension in systemic sclerosis patients. 2019

39. Quest AF, Leyton L, Párraga M. Caveolins, caveolae, and lipid rafts in cellular transport, signaling, and disease. Biochem Cell Biol. 2004;82(1):129-144.

40. Drab M, Verkade P, Elger M, et al. Loss of caveolae, vascular dysfunction, and pulmonary defects in caveolin-1 gene-disrupted mice. Science. 2001;293(5539):2449-2452.

41. Garg A, Kircher M, Del Campo M, Amato RS, Agarwal AK. Whole exome sequencing identifies de novo heterozygous CAV1 mutations associated with a novel neonatal onset lipodystrophy syndrome. Am J Med Genet A. 2015;167a(8):1796-1806.

42. Hartung A, Bitton-Worms K, Rechtman MM, et al. Different routes of bone morphogenic protein (BMP) receptor endocytosis influence BMP signaling. Mol Cell Biol. 2006;26(20):7791-7805.

43. Wertz JW, Bauer PM. Caveolin-1 regulates BMPRII localization and signaling in vascular smooth muscle cells. Biochem Biophys Res Commun. 2008;375(4):557-561.

44. Meloche J, Courchesne A, Barrier M, et al. Critical role for the advanced glycation end-products receptor in pulmonary arterial hypertension etiology. J Am Heart Assoc. 2013;2(1):e005157.

45. Maniatis NA, Shinin V, Schraufnagel DE, et al. Increased pulmonary vascular resistance and defective pulmonary artery filling in caveolin-1-/- mice. Am J Physiol Lung Cell Mol Physiol. 2008;294(5):L865-L873.

46. Bauer PM, Yu J, Chen Y, et al. Endothelial-specific expression of caveolin-1 impairs microvascular permeability and angiogenesis. Proc Natl Acad Sci U S A. 2005;102(1):204-209.

47. Zhao YY, Liu Y, Stan RV, et al. Defects in caveolin-1 cause dilated cardiomyopathy and pulmonary hypertension in knockout mice. Proc Natl Acad Sci U S A. 2002;99(17):11375-11380.

48. Bauer PM, Bauer EM, Rogers NM, et al. Activated CD47 promotes pulmonary arterial hypertension through targeting caveolin-1. Cardiovasc Res. 2012;93(4):682-693.

49. Zhao YY, Zhao YD, Mirza MK, et al. Persistent eNOS activation secondary to caveolin-1 deficiency induces pulmonary hypertension in mice and humans through PKG nitration. J Clin Invest. 2009;119(7):2009-2018 
50. Eyries M, Montani D, Girerd B, et al. Familial pulmonary arterial hypertension by KDR heterozygous loss of function. Eur Respir J. 2020;55:4

51. Chida A, Shintani M, Matsushita Y, et al. Mutations of NOTCH3 in childhood pulmonary arterial hypertension. Mol Genet Genom Med. 2014;2(3):229-239.

52. Tørring PM, Brusgaard K, Ousager LB, Andersen PE, Kjeldsen AD. National mutation study among Danish patients with hereditary haemorrhagic telangiectasia. Clin Genet. 2014;86(2):123-133.

53. Gallione CJ, Richards JA, Letteboer TG, et al. SMAD4 mutations found in unselected HHT patients. J Med Genet. 2006;43 (10):793-797.

54. Tillet E, Bailly S. Emerging roles of BMP9 and BMP10 in hereditary hemorrhagic telangiectasia. Front Genet. 2014;5:456.

55. Wooderchak-Donahue WL, McDonald J, O'Fallon B, et al. BMP9 mutations cause a vascular-anomaly syndrome with phenotypic overlap with hereditary hemorrhagic telangiectasia. Am J Hum Genet. 2013;93(3):530-537.

56. Wang G, Fan R, Ji R, et al. Novel homozygous BMP9 nonsense mutation causes pulmonary arterial hypertension: a case report. BMC Pulm Med. 2016;16:17.

57. Wang X-J, Lian T-Y, Jiang X, et al. Germline BMP9 mutation causes idiopathic pulmonary arterial hypertension. Eur Respir $J$. 2019;53:3

58. Abdalla SA, Cymerman U, Rushlow D, et al. Novel mutations and polymorphisms in genes causing hereditary hemorrhagic telangiectasia. Hum Mutat. 2005;25(3):320-321.

59. Prigoda NL, Savas S, Abdalla SA, et al. Hereditary haemorrhagic telangiectasia: mutation detection, test sensitivity and novel mutations. J Med Genet. 2006;43(9):722-728.

60. Trembath RC, Thomson JR, Machado RD, et al. Clinical and molecular genetic features of pulmonary hypertension in patients with hereditary hemorrhagic telangiectasia. $N$ Engl $J$ Med. 2001;345(5):325-334.

61. Greenwald J, Fischer WH, Vale WW, Choe S. Three-finger toxin fold for the extracellular ligand-binding domain of the type II activin receptor serine kinase. Nat Struct Biol. 1999;6(1):18-22.

62. Simonneau G, Gatzoulis MA, Adatia I, et al. Updated clinical classification of pulmonary hypertension. $\mathrm{J} \mathrm{Am}$ Coll Cardiol. 2013;62(25 Suppl):D34-D41.

63. Eyries M, Montani D, Girerd B, et al. EIF2AK4 mutations cause pulmonary veno-occlusive disease, a recessive form of pulmonary hypertension. Nat Genet. 2014;46(1):65-69.

64. Best DH, Sumner KL, Austin ED, et al. EIF2AK4 mutations in pulmonary capillary hemangiomatosis. Chest. 2014;145 (2):231-236.

65. Grünig E, Koehler R, Miltenberger-Miltenyi G, et al. Primary pulmonary hypertension in children may have a different genetic background than in adults. Pediatr Res. 2004;56(4):571-578.

66. Chida A, Shintani M, Yagi H, et al. Outcomes of childhood pulmonary arterial hypertension in BMPR2 and ALK1 mutation carriers. Am J Cardiol. 2012;110(4):586-593.

67. Thomson JR, Machado RD, Pauciulo MW, et al. Sporadic primary pulmonary hypertension is associated with germline mutations of the gene encoding BMPR-II, a receptor member of the TGF-beta family. J Med Genet. 2000;37(10):741-745.

68. Pfarr N, Fischer C, Ehlken N, et al. Hemodynamic and genetic analysis in children with idiopathic, heritable, and congenital heart disease associated pulmonary arterial hypertension. Respir Res. 2013;14(1):3.

69. Rosenzweig EB, Morse JH, Knowles JA, et al. Clinical implications of determining BMPR2 mutation status in a large cohort of children and adults with pulmonary arterial hypertension. J Heart Lung Transplant. 2008;27(6):668-674.
70. Kerstjens-Frederikse WS, Bongers EM, Roofthooft MT, et al. TBX4 mutations (small patella syndrome) are associated with childhood-onset pulmonary arterial hypertension. $J$ Med Genet. 2013;50(8):500-506.

71. Zhu N, Gonzaga-Jauregui C, Welch CL, et al. Exome sequencing in children with pulmonary arterial hypertension demonstrates differences compared with adults. Circulation. 2018;11(4): e001887.

72. Haarman MG, Kerstjens-Frederikse WS, Vissia-Kazemier TR, et al. The genetic epidemiology of pediatric pulmonary arterial hypertension. J Pediatr. 2020;225:65-73.e65.

73. Navas P, Tenorio J, Quezada CA, et al. Molecular Analysis of BMPR2, TBX4, and KCNK3 and genotype-phenotype correlations in Spanish patients and families with idiopathic and hereditary pulmonary arterial hypertension. Revista Espanola De Cardiologia. 2016;69(11):1011-1019.

74. Bohnen MS, Ma L, Zhu N, et al. Loss-of-Function ABCC8 mutations in pulmonary arterial hypertension. Circ Genom Precision Med. 2018;11(10):e002087.

75. Gräf S, Haimel M, Bleda M, et al. Identification of rare sequence variation underlying heritable pulmonary arterial hypertension. Nat Commun. 2018;9(1):1-16.

76. Hodgson J, Swietlik EM, Salmon RM, et al. Characterization of GDF2 Mutations and Levels of BMP9 and BMP10 in Pulmonary Arterial Hypertension. Am J Respir Crit Care Med. 2020;201 (5):575-585.

77. Long L, Ormiston ML, Yang X, et al. Selective enhancement of endothelial BMPR-II with BMP9 reverses pulmonary arterial hypertension. Nat Med. 2015;21(7):777-785.

78. Chida A, Shintani M, Nakayama T, et al. Missense mutations of the BMPR1B (ALK6) gene in childhood idiopathic pulmonary arterial hypertension. Circ j. 2012;76(6):1501-1508.

79. Takeda M, Otsuka F, Nakamura K, et al. Characterization of the bone morphogenetic protein (BMP) system in human pulmonary arterial smooth muscle cells isolated from a sporadic case of primary pulmonary hypertension: roles of BMP type IB receptor (activin receptor-like kinase-6) in the mitotic action. Endocrinology. 2004;145(9):4344-4354.

80. Rostama B, Peterson SM, Vary CP, Liaw L. Notch signal integration in the vasculature during remodeling. Vascul Pharmacol. 2014;63(2):97-104.

81. Pousada G, Baloira A, Valverde D. Complex inheritance in Pulmonary Arterial Hypertension patients with several mutations. Sci Rep. 2016;6:33570.

82. Egom EE, Feridooni T, Pharithi RB, et al. A natriuretic peptides clearance receptor's agonist reduces pulmonary artery pressures and enhances cardiac performance in preclinical models: new hope for patients with pulmonary hypertension due to left ventricular heart failure. Biomed Pharmacother. 2017;93:1144-1150.

83. Egom EE, Feridooni T, Pharithi RB, et al. New insights and new hope for pulmonary arterial hypertension: natriuretic peptides clearance receptor as a novel therapeutic target for a complex disease. Int $J$ Physiol Pathophysiol Pharmacol. 2017;9 (4):112-118

84. Egom EE, Maher V, El Hiani Y. Evolving use of natriuretic peptide receptor type-C as part of strategies for the treatment of pulmonary hypertension due to left ventricle heart failure. Int J Cardiol. 2019;281:172-178.

85. Egom EE-A. Pulmonary Arterial Hypertension Due to NPR-C Mutation: a Novel Paradigm for Normal and Pathologic Remodeling? Int J Mol Sci. 2019;20(12):3063.

86. Egom EE. BNP and Heart Failure: preclinical and Clinical Trial Data. J Cardiovasc Transl Res. 2015;8(3):149-157. 
87. Matzuk MM, Kumar TR, Bradley A. Different phenotypes for mice deficient in either activins or activin receptor type II. Nature. 1995;374(6520):356-360.

88. Miyazono K, Kamiya Y, Morikawa M. Bone morphogenetic protein receptors and signal transduction. $j$ Biochemistry. 2010;147(1):35-51.

89. Oh SP, Li E. The signaling pathway mediated by the type IIB activin receptor controls axial patterning and lateral asymmetry in the mouse. Genes Dev. 1997;11(14):1812-1826.

90. Pousada G, Lupo V, Cástro-Sánchez S, et al. Molecular and functional characterization of the BMPR2 gene in Pulmonary Arterial Hypertension. Sci Rep. 2017;7:1923.

91. Matsukawa N, Grzesik WJ, Takahashi N, et al. The natriuretic peptide clearance receptor locally modulates the physiological effects of the natriuretic peptide system. Proc Nat Acad Sci. 1999;96(13):7403-7408.

92. Egom EE, Feridooni T, Pharithi RB, et al. Erratum: new insights and new hope for pulmonary arterial hypertension: natriuretic peptides clearance receptor as a novel therapeutic target for a complex disease. Int $J$ Physiol Pathophysiol Pharmacol. 2017;9(5):164.

93. Egom EE-A, Feridooni T, Pharithi RB, et al. New insights and new hope for pulmonary arterial hypertension: natriuretic peptides clearance receptor as a novel therapeutic target for a complex disease. Int $J$ Physiol Pathophysiol Pharmacol. 2017;9(4):112-118.

94. Grünig E, Mereles D, Arnold K, et al. Primary pulmonary hypertension is predominantly a hereditary disease. Chest. 2002;121(3 Suppl):81s-82s.

95. Aldred MA, Comhair SA, Varella-Garcia M, et al. Somatic chromosome abnormalities in the lungs of patients with pulmonary arterial hypertension. Am J Respir Crit Care Med. 2010;182 (9):1153-1160

96. Watson IR, Takahashi K, Futreal PA, Chin L. Emerging patterns of somatic mutations in cancer. Nat Rev Genet. 2013;14 (10):703-718.

97. Germain M, Eyries M, Montani D, et al. Genome-wide association analysis identifies a susceptibility locus for pulmonary arterial hypertension. Nat Genet. 2013;45(5):518-521.

98. White K, Dempsie Y, Nilsen M, Wright AF, Loughlin L, MacLean MR. The serotonin transporter, gender, and $17 \beta$ oestradiol in the development of pulmonary arterial hypertension. Cardiovasc Res. 2011;90(2):373-382.

99. West J, Cogan J, Geraci M, et al. Gene expression in BMPR2 mutation carriers with and without evidence of pulmonary arterial hypertension suggests pathways relevant to disease penetrance. BMC Med Genomics. 2008;1(1):45. doi:10.1186/1755-8794-1-45

100. Austin ED, Cogan JD, West JD, et al. Alterations in oestrogen metabolism: implications for higher penetrance of familial pulmonary arterial hypertension in females. Eur Respir J. 2009;34 (5):1093-1099. doi:10.1183/09031936.00010409

101. Roberts KE, Fallon MB, Krowka MJ, et al. Genetic risk factors for portopulmonary hypertension in patients with advanced liver disease. Am J Respir Crit Care Med. 2009;179(9):835-842. doi:10.1164/rccm.200809-1472OC

102. Archer SL, Marsboom G, Kim GH, et al. Epigenetic attenuation of mitochondrial superoxide dismutase 2 in pulmonary arterial hypertension: a basis for excessive cell proliferation and a new therapeutic target. Circulation. 2010;121(24):2661-2671. doi:10.1161/CIRCULATIONAHA.109.916098
103. White K, Loscalzo J, Chan SY. Holding our breath: the emerging and anticipated roles of microRNA in pulmonary hypertension. Pulm Circ. 2012;2(3):278-290. doi:10.4103/2045-8932.101395

104. Meloche J, Pflieger A, Vaillancourt M, et al. Role for DNA damage signaling in pulmonary arterial hypertension. Circulation. 2014;129(7):786-797. doi:10.1161/ CIRCULATIONAHA.113.006167

105. Brock M, Trenkmann M, Gay RE, et al. Interleukin-6 modulates the expression of the bone morphogenic protein receptor type ii through a novel STAT3-microRNA Cluster 17/92 Pathway. Circ Res. 2009;104(10):1184-1191. doi:10.1161/ CIRCRESAHA.109.197491

106. Long L, Ormiston ML, Yang X, et al. Selective enhancement of endothelial BMPR-II with BMP9 reverses pulmonary arterial hypertension. Nat Med. 2015;21(7):777-785. doi:10.1038/ nm. 3877

107. Morrell NW, Aldred MA, Chung WK, et al. Genetics and genomics of pulmonary arterial hypertension. Eur Respir J. 2019;53 (1):1. doi:10.1183/13993003.01899-2018

108. Drake KM, Dunmore BJ, McNelly LN, Morrell NW, Aldred MA. Correction of Nonsense BMPR2 and SMAD9 mutations by ataluren in pulmonary arterial hypertension. Am J Respir Cell Mol Biol. 2013;49(3):403-409. doi:10.1165/rcmb.2013-0100OC

109. Long L, Yang X, Southwood M, et al. Chloroquine prevents progression of experimental pulmonary hypertension via inhibition of autophagy and lysosomal bone morphogenetic protein type II receptor degradation. Circ Res. 2013;112(8):1159-1170. doi:10.1161/CIRCRESAHA.111.300483

110. Dunmore BJ, Drake KM, Upton PD, Toshner MR, Aldred MA, Morrell NW. The lysosomal inhibitor, chloroquine, increases cell surface BMPR-II levels and restores BMP9 signalling in endothelial cells harbouring BMPR-II mutations. Hum Mol Genet. 2013;22(18):3667-3679

111. Hurst LA, Dunmore BJ, Long L, et al. TNF $\alpha$ drives pulmonary arterial hypertension by suppressing the BMP type-II receptor and altering NOTCH signalling. Nat Commun. 2017;8:14079.

112. Nickel NP, Spiekerkoetter E, Gu M, et al. Elafin reverses pulmonary hypertension via caveolin-1-dependent bone morphogenetic protein signaling. Am J Respir Crit Care Med. 2015;191 (11):1273-1286.

113. Spiekerkoetter E, Tian X, Cai J, et al. FK506 activates BMPR2, rescues endothelial dysfunction, and reverses pulmonary hypertension. J Clin Invest. 2013;123(8):3600-3613.

114. Condon DF, Nickel NP, Anderson R, Mirza S, de Jesus Perez VA. The 6th World Symposium on Pulmonary Hypertension: what's old is new. F1000Research. 2019;8

115. McGoon M, Gutterman D, Steen V, et al. Screening, early detection, and diagnosis of pulmonary arterial hypertension: ACCP evidence-based clinical practice guidelines. Chest. 2004;126(1 Suppl): $14 \mathrm{~s}-34 \mathrm{~s}$.

116. Quest AFG, Leyton L, Párraga M. Caveolins, caveolae, and lipid rafts in cellular transport, signaling, and disease. Biochem Cell Biol. 2004;82(1):129-144.

117. Ketchum KA, Joiner WJ, Sellers AJ, Kaczmarek LK, Goldstein SAN. A new family of outwardly rectifying potassium channel proteins with two pore domains in tandem. Nature. 1995;376(6542):690-695.

118. Ma L, Chung WK. The role of genetics in pulmonary arterial hypertension. J Pathol. 2017;241(2):273-280. 


\section{Publish your work in this journal}

The Application of Clinical Genetics is an international, peerreviewed open access journal that welcomes laboratory and clinical findings in the field of human genetics. Specific topics include: Population genetics; Functional genetics; Natural history of genetic disease; Management of genetic disease; Mechanisms of genetic disease;
Counselling and ethical issues; Animal models; Pharmacogenetics; Prenatal diagnosis; Dysmorphology. The manuscript management system is completely online and includes a very quick and fair peerreview system, which is all easy to use. Visit http://www.dovepress. com/testimonials.php to read real quotes from published authors. 